\title{
A New Methodology for the Prediction of Burst Pressure for API 5L X Grade Flawless Pipelines
}

Do Han Oh*, Julia Race, Selda Oterkus, Enrong Chang

Department of Naval Architecture, Ocean and Marine Engineering, University of Strathclyde, Glasgow G4 0LZ, UK

*Corresponding author. Tel.: +44 7462 826146; E-mail address: 76odohan@gmail.com

\begin{abstract}
Accurate prediction of the burst pressure of a pipeline is critical for pipeline design and safe operation. It is usually achieved by using analytical and empirical formulae derived from theoretical, numerical and experimental methods.
\end{abstract}

This study was carried out to develop a new methodology to predict the burst pressure for API 5L X grade flawless pipelines. The newly proposed methodology has been developed using finite element analysis, employing a bilinear material model using the tangent modulus approach. In this approach, the strain at ultimate tensile strength has been derived from analysis of API 5L X grade material coupon test data.

A comprehensive nonlinear finite element parametric study was conducted with this bilinear material model. The results were used to derive an empirical formula for estimating the burst pressure of API 5L X grade flawless pipelines. It was found that the best agreement was achieved between the burst pressure calculated by the proposed formula and the burst test results. Therefore, it can be concluded that the burst pressure prediction empirical formula derived by following the proposed methodology can calculate an accurate burst pressure for the API 5L X grade flawless pipelines.

KEYWORDS: Burst Pressure; Flawless; Pipeline; Bilinear; API 5L 


\section{Introduction}

The burst pressure of a pipeline refers to the internal pressure that causes a pipe to burst or fracture. Accurate prediction of the burst pressure is critical for pipeline design and safe operation. It is usually achieved by using analytical and empirical formulae derived from theoretical, numerical and experimental methods.

The existing formulae to predict the burst pressure of flawless cylindrical vessels are listed in Table 1. The formulae are categorized into three different types according to the failure criterion used. The first sets of formulae use the Tresca criterion, which is defined as the occurrence of yielding when the maximum shear stress at any point reaches a maximum allowable shear stress. In this criterion, the maximum shear stress is calculated as half the difference between the maximum and minimum principal stresses. The Tresca based failure criteria include Law and Bowie (2007), ASME (1962), Barlow OD, ID or Flow (1836), Bailey-Nadai (1930), Fletcher (2003), Turner (1910), Stewart et al.(1) (1994), DNV (2013) and Max. Shear Stress (Christopher et al., 2002).

The second group of formulae are based on the von Mises criterion which assumes that failure takes place when the maximum distortion energy reaches the failure limit equal to the distortion energy required to cause yield in a tensile test. Amongst this group there are nine sets of formulae, i.e. Bohm (1972), Faupel (1956), Marin and Rimrott (1958), Marin and Sharma (1958), Soderberg (1941), Svensson (1958) and Stewart et al.(2) (1994), Nadai (1931) and Nadai (1963).

The final group of formulae applies the average shear stress criterion, which defines failure as the point when the average shear stress reaches the allowable average shear stress. The allowable average shear stress is calculated using the average of the maximum shear stress and the von Mises equivalent shear stress, as proposed by Zhu and Leis (2005; 
$2007 ; 2010 ; 2012)$.

Table 1 Existing analytical solutions to estimate the burst pressure.

Tresca Criterion Category

\begin{tabular}{|c|c|c|c|}
\hline $\begin{array}{l}\text { ASME } \\
(1962)\end{array}$ & $P_{\max }=\sigma_{U T S}\left(\frac{k-1}{0.6 k+0.4}\right)$ & DNV (2013) & $P_{\max }=\frac{2 t}{D-t} f_{c b} \frac{2}{\sqrt{3}}$ \\
\hline $\begin{array}{l}\text { Barlow OD } \\
(1836)\end{array}$ & $P_{\max }=\sigma_{U T S} \frac{2 t}{D}$ & $\begin{array}{l}\text { Fletcher } \\
(2003)\end{array}$ & $P_{\max }=\frac{2 t \sigma_{\text {flow }}}{D_{i}\left(1-\frac{\varepsilon_{U T S}}{2}\right)}$ \\
\hline $\begin{array}{l}\text { Barlow ID } \\
(1836)\end{array}$ & $P_{\max }=\sigma_{U T S} \frac{2 t}{D_{i}}$ & $\begin{array}{l}\text { Max. Shear } \\
\text { Stress } \\
(2002)\end{array}$ & $P_{\text {max }}=2 \sigma_{U T S}\left(\frac{k-1}{k+1}\right)$ \\
\hline $\begin{array}{l}\text { Barlow Flow } \\
(1836)\end{array}$ & $P_{\text {max }}=\sigma_{\text {flow }} \frac{2 t}{D_{i}}$ & $\begin{array}{l}\text { Turner } \\
(1910)\end{array}$ & $P_{\max }=\sigma_{U T S} \ln (k)$ \\
\hline $\begin{array}{l}\text { Bailey-Nadai } \\
\text { (1930) }\end{array}$ & $P_{\max }=\frac{\sigma_{U T S}}{2 n}\left(1-\frac{1}{k^{2 n}}\right)$ & $\begin{array}{l}\text { Stewart et } \\
\text { al.(1) (1994) }\end{array}$ & $P_{\max }=\frac{t}{2^{(n-1)}} \frac{\sigma_{U T S}}{D_{\text {ave }}}$ \\
\hline
\end{tabular}

von-Mises Criterion Category

Bohm (1972) $\quad P_{\text {max }}=\sigma_{U T S}\left(\frac{0.25}{0.227+n}\right)\left(\frac{e}{n}\right)^{n} \frac{2 t}{D_{i}}\left(1-\frac{t}{D_{i}}\right)$

\begin{tabular}{|c|c|c|c|}
\hline $\begin{array}{l}\text { Faupel } \\
(1956)\end{array}$ & $P_{\text {max }}=\frac{2}{\sqrt{3}} \sigma_{\text {yield }}\left(2-\frac{\sigma_{\text {yield }}}{\sigma_{U T S}}\right) \ln (k)$ & $\begin{array}{l}\text { Nadai } \\
(1963)\end{array}$ & $P_{\max }=\frac{\sigma_{U T S}}{\sqrt{3} n}\left(1-\frac{1}{k^{2 n}}\right)$ \\
\hline $\begin{array}{l}\text { Marin and } \\
\text { Rimrott } \\
(1958)\end{array}$ & $P_{\max }=\frac{2}{\sqrt{3}} \frac{\sigma_{U T S}}{\left(1+\varepsilon_{U T S}\right)} \ln (k)$ & $\begin{array}{l}\text { Soderberg } \\
\text { (1941) }\end{array}$ & $P_{\max }=\frac{4}{\sqrt{3}} \sigma_{U T S}\left(\frac{k-1}{k+1}\right)$ \\
\hline $\begin{array}{l}\text { Marin and } \\
\text { Sharma } \\
(1958)\end{array}$ & $P_{\max }=\frac{4 t}{(\sqrt{3})^{(n+1)}} \frac{\sigma_{U T S}}{D_{i}}$ & $\begin{array}{l}\text { Svensson } \\
(1958)\end{array}$ & $\begin{array}{l}P_{\max } \\
=\sigma_{U T S}\left(\frac{0.25}{0.227+n}\right)\left(\frac{e}{n}\right)^{n} \ln (k)\end{array}$ \\
\hline Nadai (1931) & $P_{\max }=\frac{2}{\sqrt{3}} \sigma_{U T S} \ln (k)$ & $\begin{array}{l}\text { Stewart et } \\
\text { al.(2) (1994) }\end{array}$ & $P_{\max }=\frac{4 t}{(\sqrt{3})^{(n+1)}} \frac{\sigma_{U T S}}{D_{\text {ave }}}$ \\
\hline
\end{tabular}

Average Shear Stress Yield Criterion Category

$\begin{array}{lll}\text { Zhu and Leis } & P_{\text {max }}=\left(\frac{2+\sqrt{3}}{4 \sqrt{3}}\right)^{n+1} \frac{4 t \sigma_{U T S}}{D_{\text {ave }}} & \begin{array}{l}\text { Zhu and } \\ \text { Leis }(2007)\end{array}\end{array} \quad P_{\max }=\left(\frac{2+\sqrt{3}}{4 \sqrt{3}}\right)^{q} \frac{4 t \sigma_{U T S}}{D_{\text {ave }}}$

\section{Where}

$P_{\text {max }}:$ Burst Pressure

$t$ : pipe wall thickness

$\varepsilon_{U T S}:$ strain at UTS

$D_{i}, D, D_{\text {ave }}$ : Pipe inner, outer and

$\sigma_{y i e l d}, \sigma_{U T S}$ yield and ultimate tensile

average diameter, respectively strength of pipe material, respectively

$$
q=1+0.239\left(\frac{1}{Y T}-1\right)^{0.596}
$$

$k=\frac{D}{D_{i}}$, only for ASME: $\mathrm{k}<1.5$ )

$f_{c b}=\operatorname{Min} .\left[\sigma_{y} ; \frac{\sigma_{U T S}}{1.15}\right]$

$\mathrm{YT}=\frac{\sigma_{\text {yield }}}{\sigma_{U T S}}$

$\sigma_{\text {flow }}=\frac{\sigma_{\text {yield }}+\sigma_{U T S}}{2}$

$n=\ln \left(1+\varepsilon_{U T S}\right)$

$e=$ Euler's number

Zhu and Leis $(2007 ; 2012)$ compared the burst pressures predicted by all of the formulae in Table 1 with experimental burst tests results for pipelines. The results showed that there are discrepancies between the burst pressure calculated by equations, this is because most 
of these formulae were developed from either simple theoretical methods or empirical fits to a limited set of experimental data for the specific material considered. In other words, it is not straightforward to get a single formula that was accurately able to predict the burst pressure over the range of the tests performed.

Therefore, in order to be able to define or develop an accurate formula for burst pressure over a range of pipeline geometries and materials, a large and representative set of experimental data is required. However, pipeline burst experiments can be expensive and time consuming to conduct. Therefore, researchers use numerical methods to determine the burst pressure of pipelines; the most commonly used of which is nonlinear Finite Element Analysis (FEA). When performing nonlinear FEA to determine the burst pressure of pipelines, it is necessary to define the limit load criterion. A review of the literature has indicated that there are a number of different limit load criteria employed in FEA analysis and these are described in the following section.

The development of the empirical formula to predict the burst pressure of flawless pipelines was conducted by following the procedure illustrated in Figure 1.

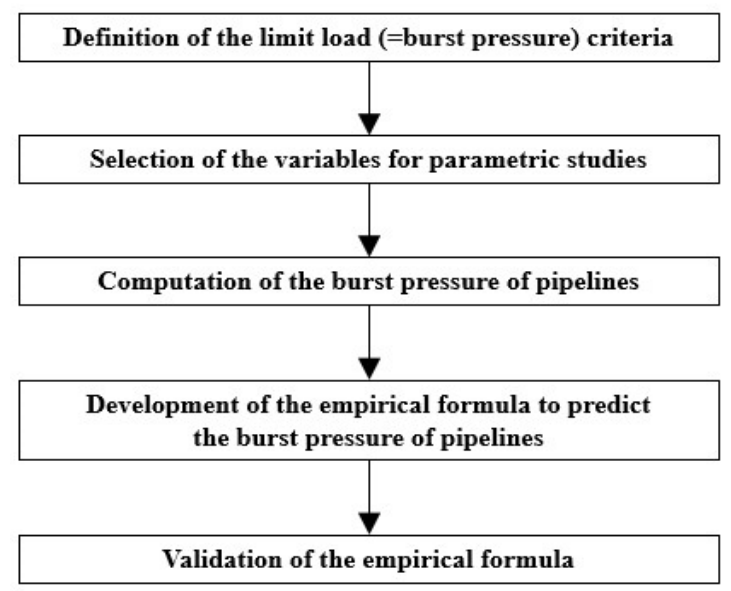

Figure 1 Procedure for the development of the empirical formula to predict the burst pressure of flawless pipelines.

\subsection{Review of Limit Load Criteria}


The differences between the reviewed limit load criteria are illustrated on schematic loading plots presented in Figures 2 (a-d).

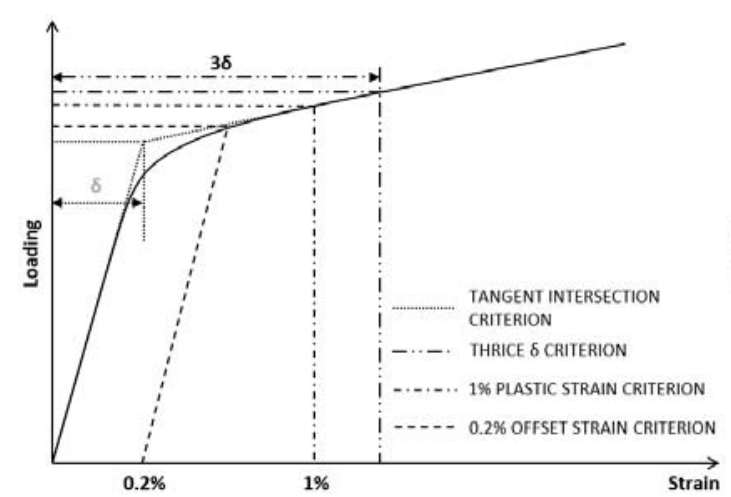

(a)

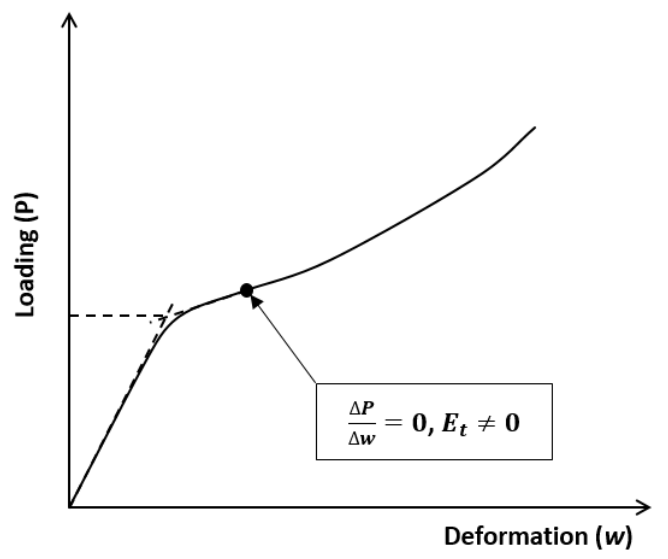

(c)

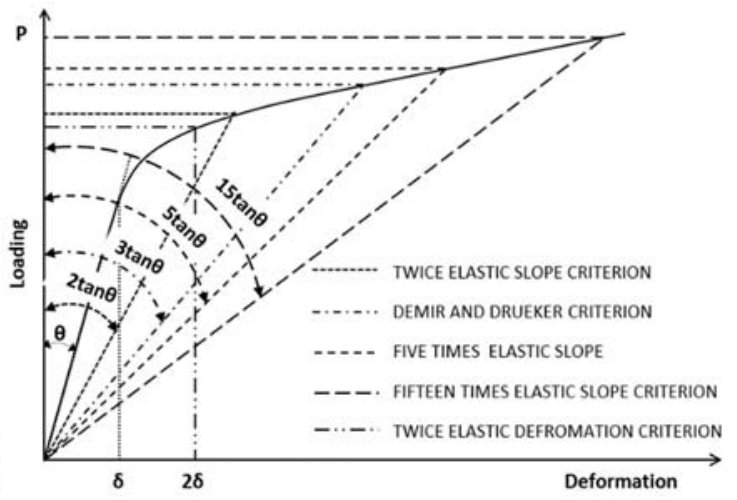

(b)

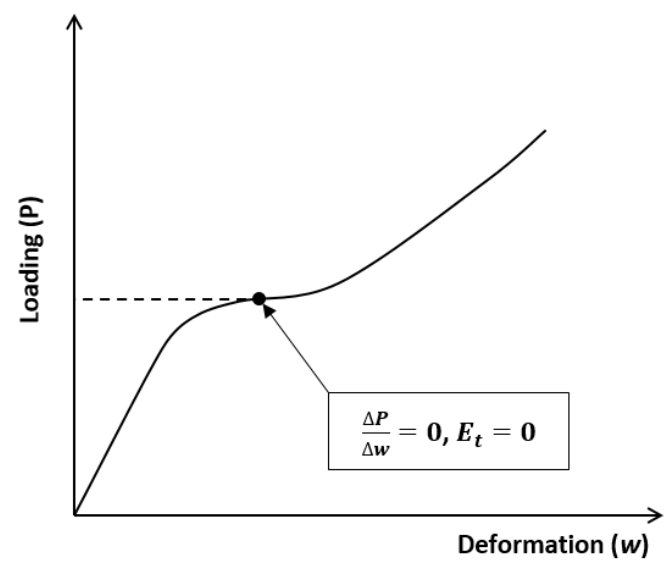

(d)

Figure 2 Criteria for limit load estimation: (a) tangent intersection and strain based criteria, (b) elastic slope and deformation based criteria, (c) zero curvature criterion with non-zero tangent value at the inflection point, (d) Zero curvature criterion with tangent value at the inflection point.

Figure 2(a) presents the strain-based criterion. In the $1 \%$ plastic strain criterion (Figure 2(a)), proposed by Townley et al. (1971), the limit load is defined as the load that induces a plastic strain of $1 \%$ in the material. Save (1972) suggested the tangent intersection criterion i.e. the limit is represented by the load at the intersection between tangents of the elastic and plastic parts of the loading-deformation curve. The limit load in the thrice $\delta$ criterion (Schroeder, 1985) is defined as the load where its deformation reaches three times the tangent intersection load proposed by Save (1972).

Several criteria are included in ASME codes $(1971 ; 1974 ; 1986)$. They are the $0.2 \%$ offset 
strain, twice elastic deformation and twice elastic slope criterion. The limit load for the $0.2 \%$ offset strain criterion is given by the load corresponding to the intersection of the line parallel to the elastic slope at the plastic strain of $0.2 \%$ and the stress-strain curve as shown in Figure 2 (a). The twice elastic deformation criterion defines the limit load as the load at the point where the magnitude of the deformation is twice the elastic deformation at yield whilst the load at the intersection point between the twice elastic slope line and the load-deformation curve is defined as the limit load in the twice elastic slope criterion as shown in Figure 2 (b). The triple elastic slope criterion defined by Demir and Drucker (1963) is similar to the twice elastic slope criterion but with the limit load defined at three times of the elastic slope at yield. Based on a similar concept, Kirkwood $(1986 ; 1989)$ proposed a five times elastic slope criterion whilst a fifteen times elastic slope criterion was defined by Lynch and Moffat (2000) as shown in Figure 2 (b).

It can be seen in Figure 2 (c) and (d) that there are two methods proposed as part of the zero curvature criterion (Zhang et al., 1989). If the tangent value at the inflection point is not zero as shown in Figure 2 (c), the limit load is determined according to the tangent intersection criterion. When the tangent value at the inflection point is zero as shown in Figure 2 (d), the limit load is the load corresponding to the inflection point on the loaddeformation curve.

The afore mentioned limit load criteria were assessed by Chen et al. (2016) by performing nonlinear FEA on a pressure vessel using an elastic perfectly plastic material model. The predictions using the different failure criteria outlined above were compared with the experimental burst test results. It was found that, in the majority of cases, the burst pressure was overestimated by the limit load predictions. In addition, it is observed from the current work that some complicated post-processing work, such as locating an 
intersection point, is required for most of these criteria in order to find the limit load.

\subsection{Definition of the Limit Load Criteria}

As a result of the review of the literature, it can be concluded that in order to be able to develop an empirical formula for predicting burst pressures of pipelines using numerical techniques, such as FEA, an objective method for determining the limit load is required. Therefore, the criterion is defined as the pressure that corresponds to be a point when the maximum von Mises equivalent stress reaches the ultimate tensile strength (UTS). The reason for selecting just one node and using the UTS of the material to define the burst pressure is to reflect the conservative approach, and the practical approach considering strain-hardening effects.

\subsection{Objectives}

One of the purposes of this research is to present an empirical formula to estimate the strain at UTS for determining a bilinear material model. The proposed formula for the strain at UTS takes into account strain hardening effects as the ratio of the yield strength to the ultimate tensile strength; this ratio is a characteristic of the strain hardening (Norman, 2013).

The other aim of this research is to develop an empirical formula to predict the burst pressure for flawless pipelines. The burst pressure prediction formula was derived from the results by the nonlinear FEA with the tangent modulus defined by the use of the calculated strain at UTS.

\section{Development of an Empirical Formula to Estimate the Strain at UTS}

In this research, a procedure for deriving an empirical formula to estimate the strain at 
UTS has been developed and is described in Figure 3.

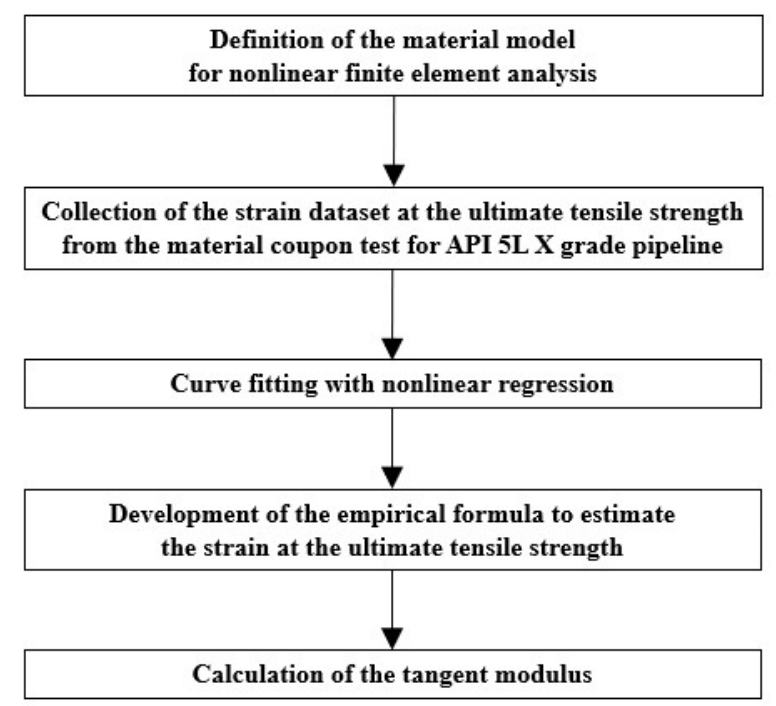

Figure 3 Flow of the methodology for the development of the empirical formula to estimate the strain at UTS of pipelines.

The selection of an appropriate material model, i.e. stress-strain curve, is critical if reliable and accurate nonlinear FEA results are to be obtained. Ideally, an actual stressstrain curve derived from a tensile test of the material being represented by the model should be used. However, this information may not be available at the early design stage and it may be expensive and time consuming to perform a material coupon test from the actual component. In practice, the bilinear material model or elastic-perfectly plastic material model are generally assumed in nonlinear FEA. In both models, two linear lines represent the elastic region and the plastic region. The slopes of the lines are known as the Young's modulus $(E)$ and tangent modulus $\left(E_{t}\right)$, respectively, as shown in Figure 4. The issue with the elastic perfectly plastic material model is that the strain hardening effect is not considered and thus it usually produces a fairly conservative result. A bilinear material model, as shown in Figure 4, which considers strain hardening is therefore proposed in this study. 


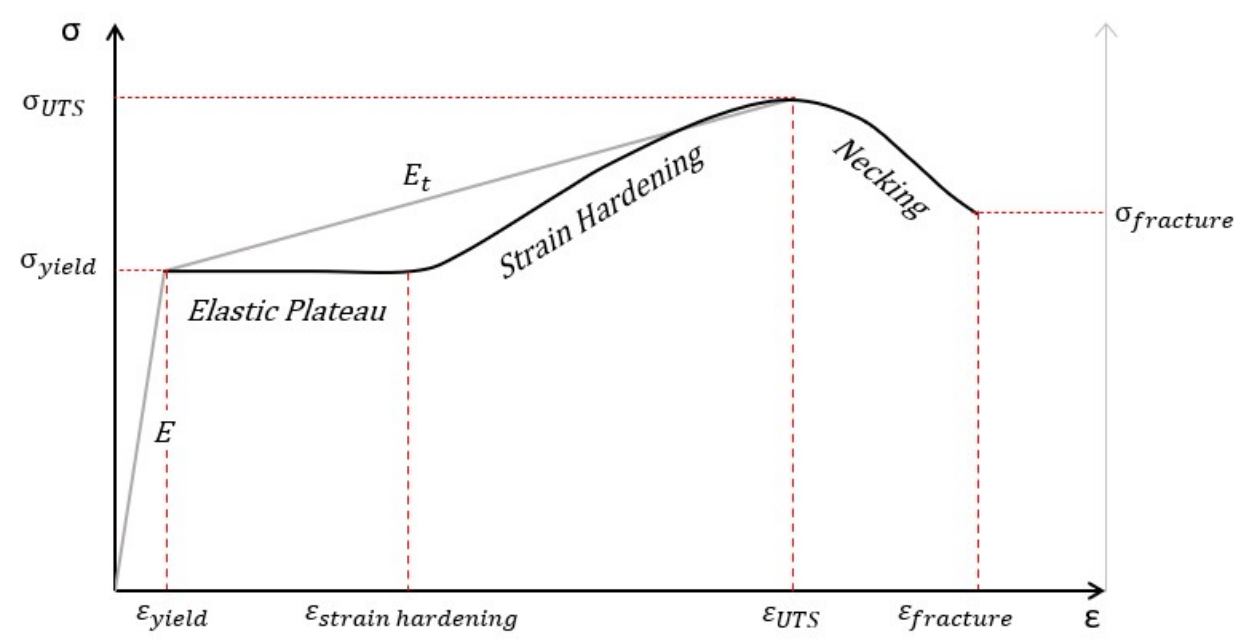

Figure 4 Typical Stress-strain cureve of carbon steel and bilinear material model for FEA.

For the plastic region, $E_{t}$ is defined by the following formula (1):

$$
E_{t}=\frac{\sigma_{U T S}-\sigma_{\text {yield }}}{\varepsilon_{U T S^{-}}-\varepsilon_{\text {yield }}}
$$

where $\varepsilon_{y i e l d}$ and $\varepsilon_{U T S}$ are the strain at yield strength and UTS. The values for $\sigma_{U T S}$, $\sigma_{y i e l d}$ and $\varepsilon_{y i e l d}$ can be readily obtained for different pipeline materials. However, the $\varepsilon_{U T S}$ is usually not readily available and can only be obtained from an experimental stressstrain curve data. For this reason, MacDonald (2007) mentioned that $E_{t}$ can be calculated using $\varepsilon_{\text {fracture }}$ instead of $\varepsilon_{U T S}$, and formula (1) can be expressed as follows:

$$
E_{t}^{\prime}=\frac{\sigma_{U T S}-\sigma_{\text {yield }}}{\varepsilon_{\text {fracture }}-\varepsilon_{\text {yield }}}
$$

where $\varepsilon_{\text {fracture }}$ is the strain at fracture. However, it can be seen from Figure 4 that $\varepsilon_{\text {fracture }}$ is usually larger than $\varepsilon_{U T S}$ for pipeline materials. Thus, the tangent modulus $E t$ is underestimated if formula (2) is used.

In this study, a dataset of measurements of strain at UTS from material coupon test data for API 5L X52, X65, X70 and X80 grade pipeline has been used to derive an empirical formula to estimate $\varepsilon_{U T S}$ using curve fitting with nonlinear regression (Figure 5). The 
following exponential function (3) is assumed to predict $\varepsilon_{U T S}$ :

$$
\varepsilon_{U T S}=C_{1} \times e^{-C_{2} \omega}
$$

where $C_{1}(=63.137)$ and $C_{2}(=2.574)$ are the fit coefficients, and $\omega$ is the $\sigma_{\text {yield }}$ to $\sigma_{U T S}$ ratio.

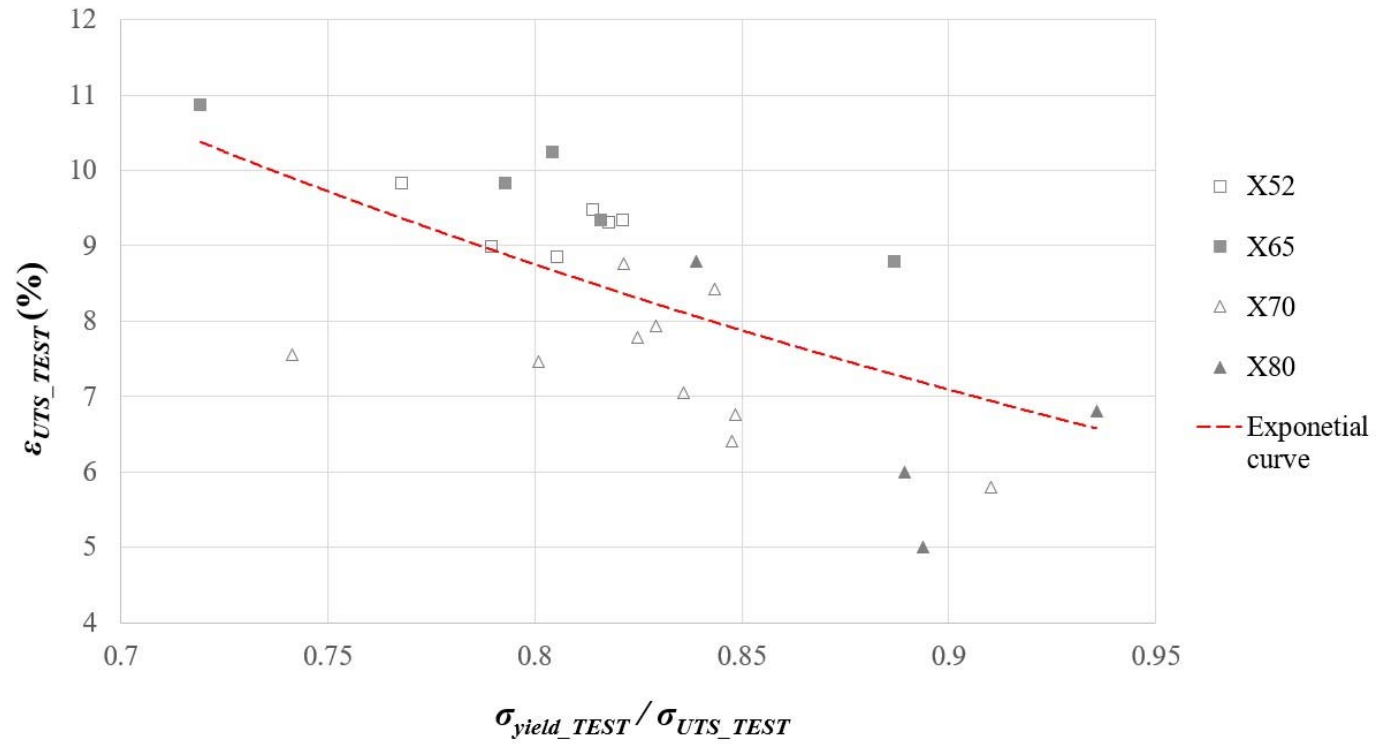

Figure 5 Material coupon test data plot and best-fit exponential curve using EUTS_TEST and the ratio of $\sigma_{y i e l d}$ TEST to $\sigma U T S_{-} T E S T$.

To validate the proposed formula, the Pearson Product-Moment Correlation Coefficient (PPMCC) was employed. The PPMCC is commonly used as a measure of the linear relationship between two quantitative variables and is calculated by the following formula (4):

$$
\operatorname{PPMCC}(r)=\frac{\sum(x-\bar{x})(y-\bar{y})}{\sqrt{\sum(x-\bar{x})^{2} \sum(y-\bar{y})^{2}}}
$$

Where $\mathrm{x}$ and $\mathrm{y}$ are the strain calculated by the proposed formula and from the material coupon test, respectively and $\bar{x}$ and $\bar{y}$ are the average values of $\mathrm{x}$ and $\mathrm{y}$ groups of values, respectively. Evans (1996) proposed guidance for the strength of the correlation expressed by the limit of the absolute $r$-value as shown in Table 2 . 
Table 2 The guidance for the strength of the correlation by Evans (1996).

\begin{tabular}{cc}
\hline Limit & Strength \\
\hline $0.00-0.19$ & very weak \\
$0.20-0.39$ & weak \\
$0.40-0.59$ & moderate \\
$0.60-0.79$ & strong \\
$0.80-1.00$ & very strong \\
\hline
\end{tabular}

Next, the $t$-value was calculated based on formula (5):

$$
t=\frac{r \sqrt{n-2}}{\sqrt{1-r^{2}}}
$$

Where $t$ is the $t$-value and $n(=25)$ is the number of observations.

According to the correlation analysis, as shown in Figure 6, the PPMCC between the strain calculated by the proposed formula and the strain from the material coupon test is 0.675 and the $t$-value is 4.39 . The probability value $\left(P_{\text {probability }}\right)$ for a two-tailed test obtained by applying $n-2$ degree of freedom $(=23)$ to the $t$ distribution function in the Excel program is 0.0002 , which is less than the 0.001 significance level $(=99.9 \%$ confidence). Hence, the null hypothesis that there is no statistically significant relationship between the strain calculated by the proposed formula and strain obtained from the material coupon test $(\mathrm{PPMCC}=0)$ is rejected. Therefore, the relationship between the strain calculated by the proposed formula and from the material coupon test is statistically significant with $r(23)=.675$, and $P_{\text {p probability }}<.001$. In addition, the correlation strength is strong in accordance with Table 2.

Consquently, it can be concluded that the $\varepsilon_{U T S}$ can be calculated using formula (3) for API 5L X-grade pipeline steels from X52 to X80, and that the tangent modulus $E_{t}$ can be calculated by using formula (1) to consider the strain hardening effect. This bilinear material model, derived from the proposed methodology, is used for nonlinear FEA in 
this study. The advantage of the proposed method is that it is possible to determine the strain at UTS using the basic material information of $\sigma_{y i e l d}$ to $\sigma_{U T S}$ ratio. Consequently, the bilinear stress-strain model may be estimated without the need to perform the tensile tests, which may save time and cost at the early design stage.

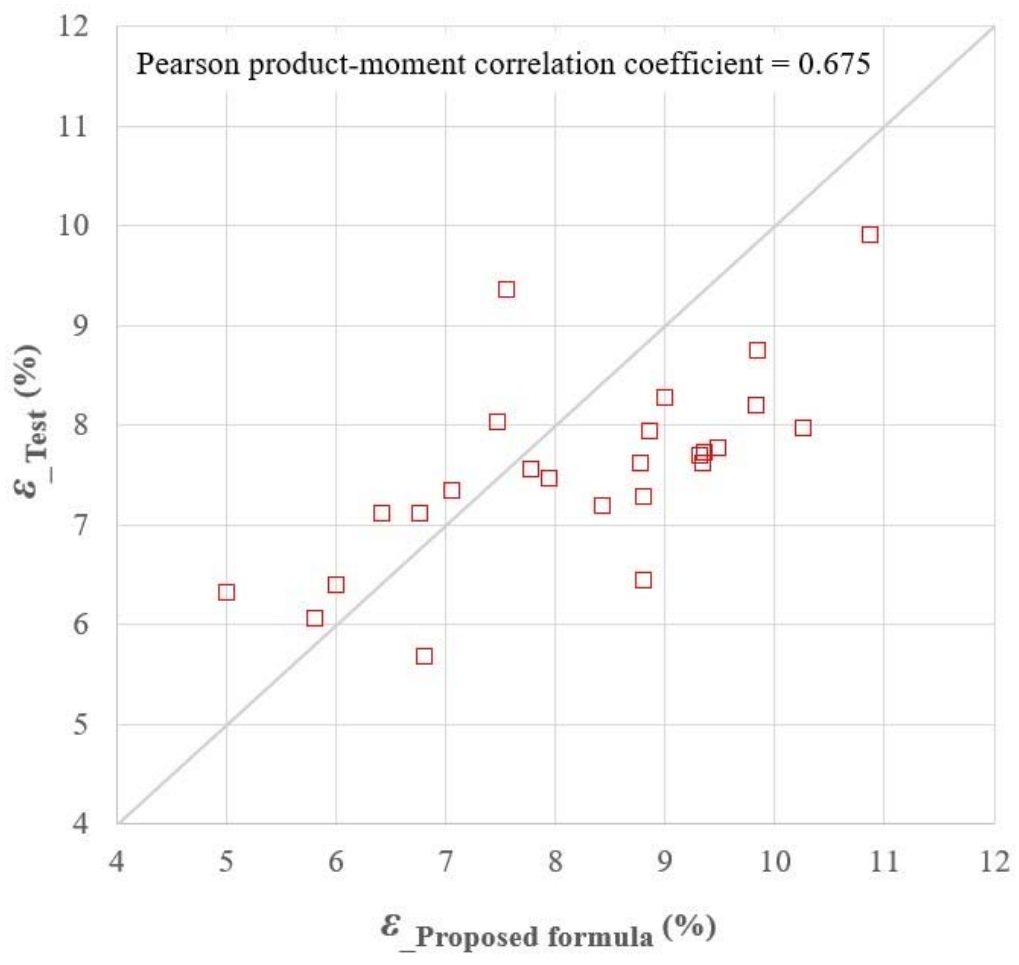

Figure 6 Pearson product-moment correlation between the strain calculated by the proposed formula and the strain from the material coupon test.

\section{Nonlinear Finite Element Analyses}

In this study, the commercial software ANSYS Mechanical APDL versions 17.1 is used to model and perform the static nonlinear analysis for flawless pipelines under internal pressure only. In addition, it is assumed that the pipeline is a very long, thin-walled pipeline, so the shrinkage of the longitudinal direction due to the Poisson's ratio is negligible. The following sections describe the setup of the ANSYS model used to perform the parametric study.

\subsection{Geometric Information and Material Property}


The geometric information and material properties for the API X70 model used in the convergence study are shown in Table 3 and 4, respectively.

Table 3 Geometric information of API X70 for setting up of FEA model.

\begin{tabular}{ccc}
\hline Outer diameter $(\mathrm{mm})$ & Thickness $(\mathrm{mm})$ & Model length $(\mathrm{mm})$ \\
\hline 762 & 15.9 & 5 times of outer diameter $(=3810)$ \\
\hline
\end{tabular}

Table 4 Material properties of API X70 for setting up of FEA model.

\begin{tabular}{ccccc}
\hline $\begin{array}{c}\text { Young's } \\
\text { modulus } \\
(\mathrm{MPa})\end{array}$ & $\begin{array}{c}\text { Tangent } \\
\text { modulus } \\
(\mathrm{MPa})\end{array}$ & $\begin{array}{c}\text { Poisson's } \\
\text { ratio }\end{array}$ & $\begin{array}{c}\text { Yield strength } \\
(\mathrm{MPa})\end{array}$ & $\begin{array}{c}\text { Ultimate tensile } \\
\text { Strength } \\
(\mathrm{MPa})\end{array}$ \\
\hline 207,000 & 1220.1 & 0.3 & 482.63 & 565.37 \\
\hline
\end{tabular}

\subsection{Material Model}

The bilinear material model as described in chapter 2 is used in the FEA as follows. Firstly, $\varepsilon_{U T S}$ was estimated from the derived formula (3) and used to calculate the tangent modulus in order to consider the strain hardening effect in the plastic region. The calculated tangent modulus is $1220.1 \mathrm{MPa}$ as shown in Table 4.

\subsection{Definition of the Finite Element Type}

The Plane 183 element has been selected to model the pipeline for two reasons. Firstly, this element can support axisymmetric analysis, that is, by using this element, the number of elements required to model the pipeline and the consequent computing time can be reduced. Secondly, this higher order 2-D and 8-node element can provide more accurate results.

\subsection{Applied Load and Boundary Condition}

The applied load and boundary conditions are shown in Figure 7. As a load condition, the internal pressure acts on the inside of the pipeline and is increased. Axisymmetry and 
symmetry boundary conditions are considered to simplify the model. First, the longitudinal direction of FE model should coincide with the global Y-axis to apply the axisymmetry boundary condition. In addition, according to the assumption mentioned in the beginning of this chapter, as the considered pipeline is a very long, thin-walled pipeline, there is no longitudinal shrinkage by the Poisson's ratio. Therefore, the symmetry boundary condition has been applied to both ends of the pipeline FE model.

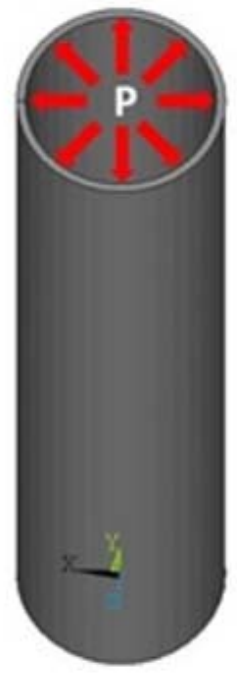

(a)

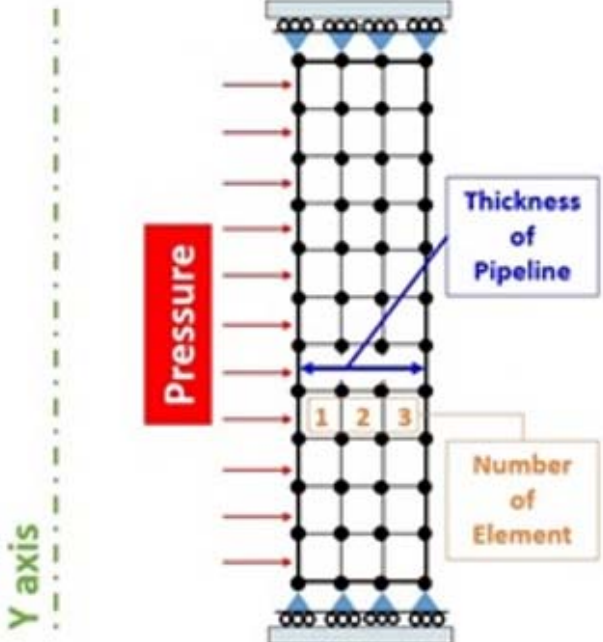

(b)

Figure 7 Pipeline finite element model mesh size, load and boundary condition: (a) loading condition, (b) mesh size, loading condition and boundary condition.

\subsection{Convergence Study for Mesh Size}

A convergence study was conducted to identify the optimum number of elements in the model through the wall thickness as shown in Figure 7 (b). Four different models were created with between one and four elements in the pipe wall. The results for the von Mises equivalent stress and the burst pressure for the four models at different number of elements are shown in Figure 8. 


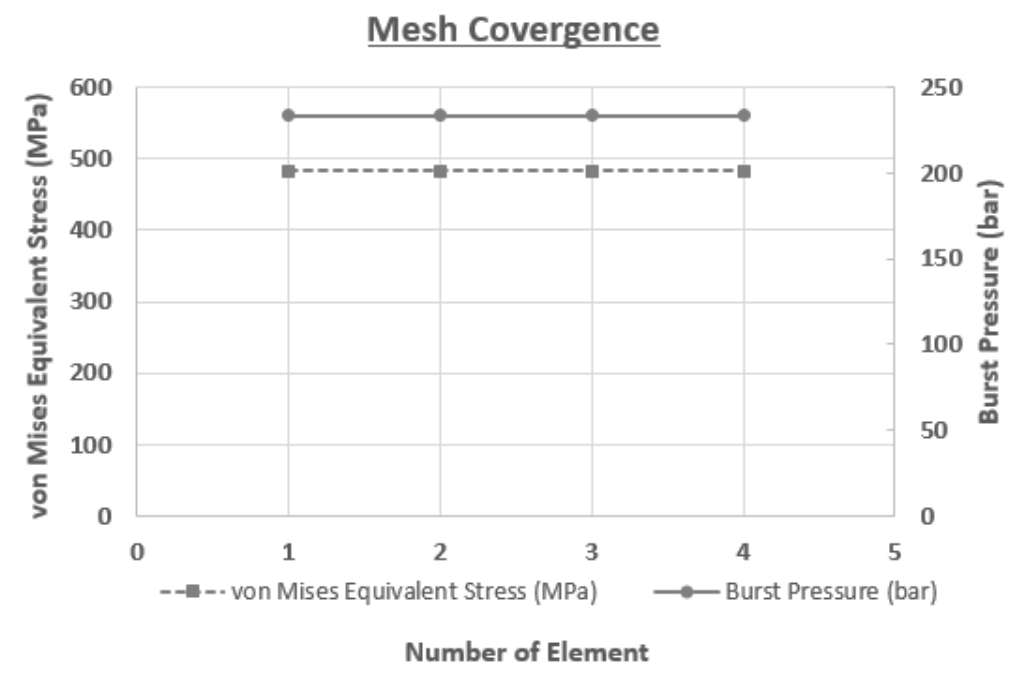

Figure 8 von Mises equivalent stress and burst pressure according to the number of element.

It can be seen from this plot that the number of elements through the wall thickness does not affect the result. However, in order to be able to investigate the stress distribution through the wall thickness, three elements were chosen for this study.

In the case of FEA model length, it is recommended that at least one diameter of the pipeline should be included in the FE-model (DNV, 2008). Consequently, the length of FEA model has been taken to be more than five times the pipeline outer diameter to avoid the effects on the constraints.

\subsection{Determining Burst Pressure Using FEA}

In this study, the burst pressure is defined as the pressure that corresponds to be a point when the maximum von Mises equivalent stress, determined using FEA, reaches the UTS at any node. Figure 9 depicts the plot of the von Mises equivalent stress against the applied pressures from the FEA results. According to the burst pressure criterion defined in section 1.2, the stress values determined before and after the UTS, indicated by the dotted circle in Figure 9 are used to obtain the burst pressure through linear interpolation or extrapolation of the UTS value. 


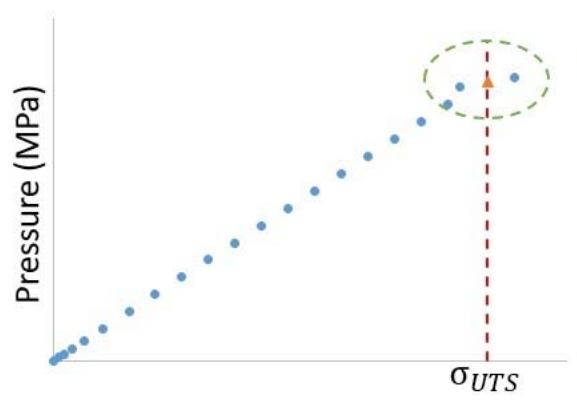

von. Mises equivalent stress (MPa)

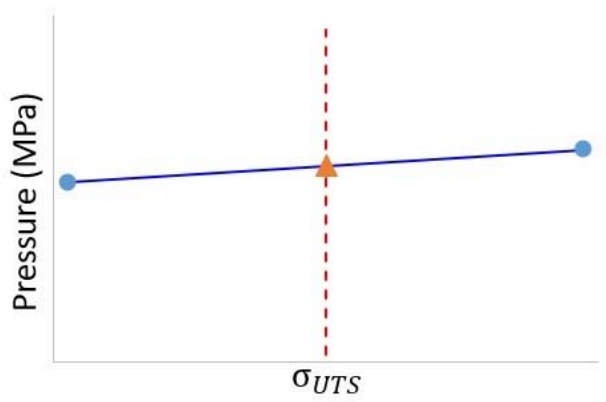

von. Mises equivalent stress (MPa)

Figure 9 Interpreting FEA results to obtain the burst pressure.

\section{Parametric Studies}

To derive a reliable empirical formula for predicting the burst pressure for API 5L X grade pipeline (API, 2004), models for different pipeline materials, diameters and thicknesses, conforming to the ranges in the API 5L pipeline code, were selected. As listed in Table A.1 in the appendix, 79 models for the X80 pipeline and 90 models per each grade from X52 to X70 were modelled for nonlinear FEA. In total, 529 parametric case studies were conducted. Material properties and geometric information of the FEA models for the parametric studies are listed in Table 5 and 6 , respectively. The tangent modulus and the strain at ultimate tensile strength, to carry out nonlinear FEA with a bilinear material model, was defined using formula (1) and the proposed formula (3), respectively.

Table 5 Material properties assumed for the FEA model for parametric studies.

\begin{tabular}{c|cccccc}
\hline Material & X52 & X56 & X60 & X65 & X70 & X80 \\
\hline Poisson's ratio & \multicolumn{7}{c}{0.3} \\
Young's modulus $(E, \mathrm{MPa})$ & \multicolumn{7}{c}{207,000} \\
$\begin{array}{c}\text { Tangent modulus }\left(E_{t}, \mathrm{MPa}\right) \\
\begin{array}{c}\text { Yield strength } \\
\left(\boldsymbol{\sigma}_{\text {yield }}, \mathrm{MPa}\right)\end{array}\end{array}$ & 1186 & 1276 & 1317 & 1187 & 1220 & 1123 \\
& 358.53 & 386.11 & 413.69 & 448.16 & 482.63 & 551.58
\end{tabular}


Ultimate tensile strength

$\left(\sigma_{U T S}, \mathrm{MPa}\right)$

$\sigma_{y i e l d} / \sigma_{U T S}$
455.05

0.788
489.53

517.11

530.90

565.37

620.53

Table 6 Geometric information and bounding cases about the FEA model for parametric studies.

\begin{tabular}{|c|c|c|c|c|c|c|}
\hline \multirow[b]{2}{*}{ Material } & \multicolumn{6}{|c|}{ Bounding cases } \\
\hline & $\mathrm{X} 52$ & $\mathrm{X} 56$ & X60 & X65 & $\mathrm{X} 70$ & $\mathrm{X} 80$ \\
\hline Outer diameter $(D, \mathrm{~mm})$ & \multicolumn{5}{|c|}{$60.3-610$} & $323.9-609.6$ \\
\hline Thickness $(t, m m)$ & \multicolumn{5}{|c|}{$3.9-50.8$} & $4.775-15.875$ \\
\hline$D / t$ & \multicolumn{5}{|c|}{$10.0-64.08$} & $25.5-96.0$ \\
\hline
\end{tabular}

\section{FEA Parametric Study Results}

As can be seen in Figure 10, a typical von Mises equivalent stress distribution of the results of parametric studies is plotted, and expressed using the 2D Axi-Symmetric full expansion plotting option of ANSYS.

Based on point $\mathrm{A}$, the burst pressure is obtained according to the method outlined in Section 3.6, i.e. the pipeline is considered to have failed when the von Mises stress at a node has exceeded the UTS of the material. 


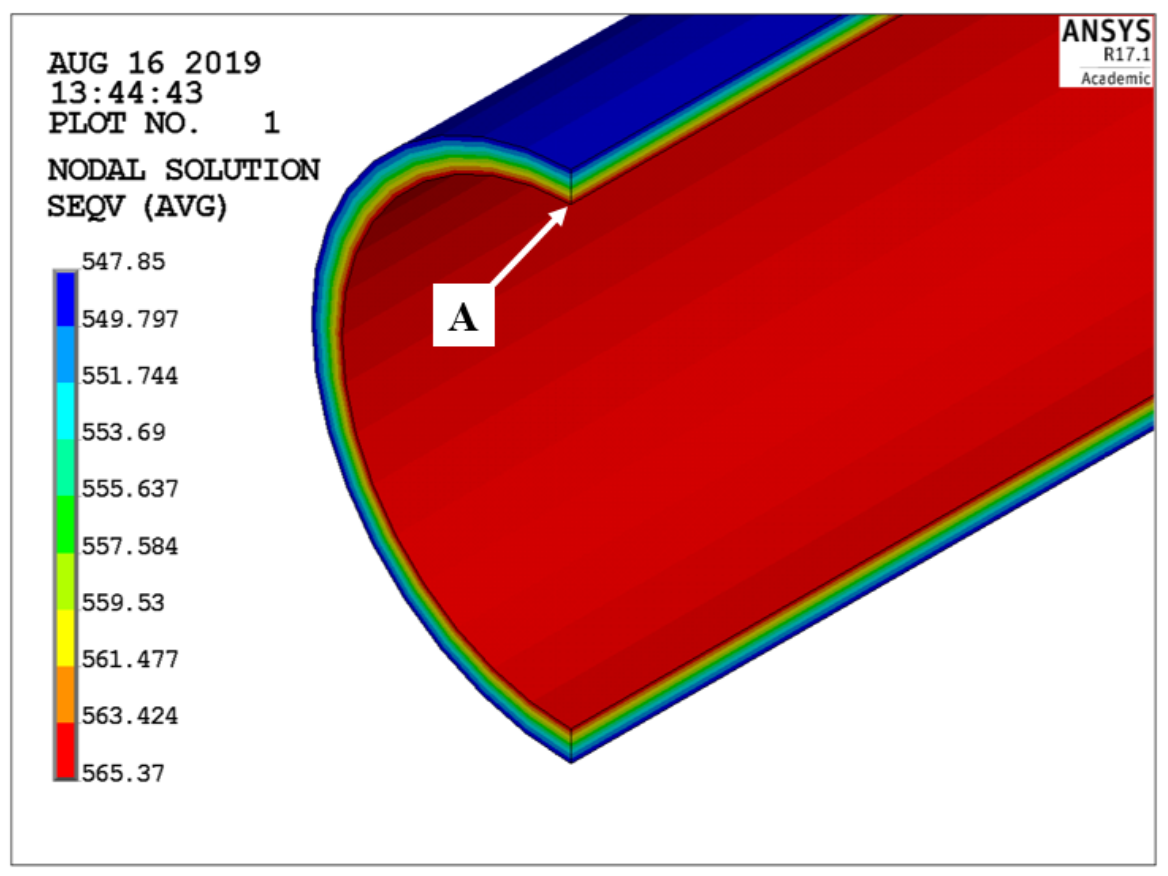

Figure 10 Sample of von Mises equivalent stress distribution of FEA results (2D AxiSymmetric full expansion plot).

The von Mises equivalent stress is related to the principal stress by formula (6) and the principal stresses are defined by three directional stresses as following; $\sigma_{1}=\sigma_{\text {hoop }}$, $\sigma_{2}=\sigma_{\text {axial }}$ and $\sigma_{3}=\sigma_{\text {radial }}$.

$$
\sigma_{\text {equi. }}=\left[\frac{\left(\sigma_{1}-\sigma_{2}\right)^{2}+\left(\sigma_{2}-\sigma_{3}\right)^{2}+\left(\sigma_{3}-\sigma_{1}\right)^{2}}{2}\right]^{0.5}
$$

\section{Derivation of Empirical Formula for Burst Pressures Prediction}

Based on the FEA results of the burst pressure from the 529 individual cases, a new empirical formula, of the form of a power law for API 5L X grade material, was derived from non-linear regression and expressed as formula (7). FEA results of the burst pressure for each material grade are plotted in Figure 11, and all of the data could be fitted to the power law curve with $\mathrm{R}$ squared $\left(\mathrm{R}^{2}=0.9992\right)$.

$$
\frac{P_{\text {Burst }}}{\sigma_{U T S}}=a\left(\frac{D}{t}\right)^{m}
$$


where $a(=2.3824)$ and $m(=-1.035)$ are the power function coefficients, $D$ is the pipeline outer diameter and $t$ is the pipeline thickness. Consequently, the empirical formula to predict the burst pressure becomes:

$$
P_{\text {Burst }}=\sigma_{U T S} \times 2.3824 \times\left(\frac{D}{t}\right)^{-1.035}
$$

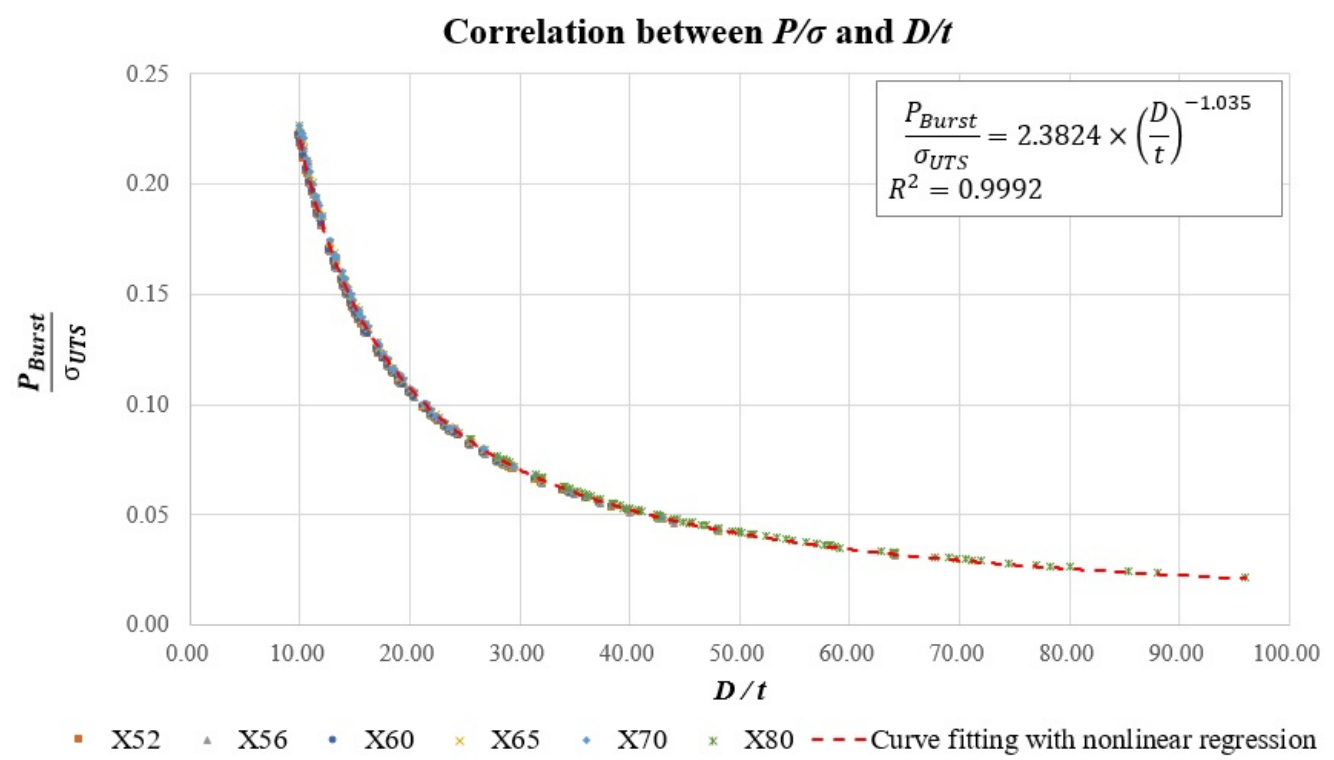

Figure 11 The Correlation between $P_{\text {Burst }} / \sigma_{U T S}$ and $D / t$ and $R$ squared $\left(R^{2}\right)$.

Formula (8) is only valid for the range of the parametric study, i.e. for the API 5L X grade flawless pipelines from $\mathrm{X} 52$ to $\mathrm{X} 80$ and the ratio of $D$ to $t$ of pipelines ranging from 10 to 96 .

\section{Validation of the Proposed Empirical Formulae}

The newly derived empirical formulae (3) and (8) have been validated by comparison with 14 burst pressure experimental results and burst pressure calculation results based on analytical methods from the literature reviewed in chapter 1. The geometric information and material properties for these 14 test specimens (Zhu and Leis, 2012; Law and Bowie, 2007; Liessem et al., 2004; Zhang et al., 2014) are listed in Table 7 below. 
Table 7 Geometric information and material properties about 14 experimental specimens.

\begin{tabular}{|c|c|c|c|c|c|c|c|}
\hline $\begin{array}{c}\text { Test } \\
\text { No. }\end{array}$ & Material & $\begin{array}{c}\text { Outer } \\
\text { diameter } \\
(D, \mathrm{~mm})\end{array}$ & $\begin{array}{c}\text { Thickness } \\
(t, \mathrm{~mm})\end{array}$ & $D / t$ & $\begin{array}{c}\text { Yield strength } \\
\left(\sigma_{\text {yield }}, \mathrm{MPa}\right)\end{array}$ & $\begin{array}{c}\text { Ultimate tensile } \\
\text { strength } \\
\left(\sigma_{U T S}, \mathrm{MPa}\right)\end{array}$ & $\sigma_{\text {yield }} / \sigma_{\text {UTS }}$ \\
\hline 1 & $\mathrm{X} 60(1)$ & 762.00 & 14.40 & 52.92 & 501.0 & 543.0 & 0.923 \\
\hline 2 & $\mathrm{X} 60(2)$ & 762.00 & 14.40 & 52.92 & 543.0 & 568.0 & 0.956 \\
\hline 3 & $\mathrm{X} 65(1)$ & 273.14 & 7.10 & 38.47 & 587.0 & 662.0 & 0.887 \\
\hline 4 & $\mathrm{X} 65(2)$ & 1016.00 & 16.90 & 60.12 & 641.0 & 683.0 & 0.939 \\
\hline 5 & $\mathrm{X} 65(3)$ & 1016.00 & 16.90 & 60.12 & 668.0 & 695.0 & 0.961 \\
\hline 6 & $\mathrm{X} 70(1)$ & 457.20 & 9.97 & 45.86 & 637.0 & 700.0 & 0.910 \\
\hline 7 & $\mathrm{X} 70(2)$ & 914.40 & 19.10 & 47.87 & 534.0 & 553.0 & 0.939 \\
\hline 8 & $\mathrm{X} 70(3)$ & 914.40 & 19.10 & 47.87 & 562.0 & 570.0 & 0.986 \\
\hline 9 & $\mathrm{X} 70(4)$ & 610.00 & 18.90 & 32.28 & 539.5 & 606.5 & 0.890 \\
\hline 10 & $\mathrm{X} 70(5)$ & 1016.00 & 16.90 & 60.12 & 593.0 & 656.5 & 0.903 \\
\hline 11 & $\mathrm{X} 80(1)$ & 356.90 & 6.96 & 51.28 & 568.0 & 677.0 & 0.839 \\
\hline 12 & $\mathrm{X} 80(2)$ & 356.17 & 6.91 & 51.54 & 640.0 & 684.0 & 0.936 \\
\hline 13 & $\mathrm{X} 80(3)$ & 1219.20 & 18.30 & 66.62 & 640.0 & 719.0 & 0.890 \\
\hline 14 & $\mathrm{X} 80(4)$ & 1219.20 & 18.30 & 66.62 & 715.0 & 744.0 & 0.961 \\
\hline
\end{tabular}

The experimental specimens in Table 7 were selected to cover different API 5L X60, $\mathrm{X} 65, \mathrm{X} 70$, and X80 grades and a range of pipeline diameters and thicknesses. Furthermore, the predictions from this study were also compared with those from the 21 burst pressure formulae detailed in Table 1. The detailed comparison results are listed in Table 8 and Figure 12.

To evaluate the accuracy of the proposed formula (8), the following statistical standard error formula (9) in association with the experimental results and the prediction results by analytical methods is applied:

$$
\text { Standard Error }(\mathrm{SE})=\sqrt{\frac{\sum\left(\frac{\left.{ }^{P_{\text {predict }}}-1\right)^{2}}{P_{\text {exp }}}\right.}{N(N-1)}}
$$

where $P_{\text {predict}}, P_{\exp }$ and $N$ denotes the predicted burst pressure, experimental results and total number of data, respectively. 
Table 8 Average Discrepancy (AD) and Standard Error (SE).

\begin{tabular}{|c|c|c|c|c|c|c|c|}
\hline \multicolumn{2}{|r|}{ Model } & \multicolumn{6}{|c|}{ Test Case } \\
\hline No. & Name & X60 (1) & X60 (2) & X65 (1) & X65 (2) & X65 (3) & $\mathrm{X} 70(1)$ \\
\hline \multicolumn{2}{|c|}{$\begin{array}{c}\text { Experimental Burst } \\
\text { Pressure }(\mathrm{MPa})\end{array}$} & 20.90 & 21.90 & 36.33 & 23.60 & 24.30 & 30.53 \\
\hline & & \multicolumn{6}{|c|}{ Burst pressures ratio $\left(P_{F P \text { formula }} / P_{\text {exp. }}\right)$} \\
\hline 1 & $\begin{array}{l}\text { ASME } \\
(1962)\end{array}$ & 1.00 & 1.00 & 0.97 & 1.00 & 1.00 & 1.02 \\
\hline 2 & $\begin{array}{l}\text { Barlow OD } \\
\quad(1836)\end{array}$ & 0.98 & 0.98 & 0.95 & 0.98 & 0.98 & 1.00 \\
\hline 3 & $\begin{array}{l}\text { Barlow ID } \\
\text { (1836) }\end{array}$ & 1.02 & 1.02 & 1.00 & 1.02 & 1.02 & 1.05 \\
\hline 4 & $\begin{array}{c}\text { Barlow flow } \\
\quad(1836)\end{array}$ & 0.98 & 1.00 & 0.94 & 1.00 & 1.02 & 1.00 \\
\hline 5 & $\begin{array}{l}\text { Bailey-Nadai } \\
\text { (1930) }\end{array}$ & 1.00 & 1.00 & 0.97 & 1.00 & 1.00 & 1.02 \\
\hline 6 & $\begin{array}{c}\text { DNV } \\
(2013)\end{array}$ & 1.00 & 1.00 & 0.98 & 1.00 & 1.00 & 1.03 \\
\hline 7 & $\begin{array}{l}\text { Fletcher } \\
\text { (2003) }\end{array}$ & 1.00 & 1.01 & 0.99 & 1.03 & 1.05 & 1.03 \\
\hline 8 & $\begin{array}{l}\text { Max. Shear Stress } \\
\text { (2002) }\end{array}$ & 1.00 & 1.00 & 0.97 & 1.00 & 1.00 & 1.02 \\
\hline 9 & $\begin{array}{l}\text { Turner } \\
(1910)\end{array}$ & 1.00 & 1.00 & 0.97 & 1.00 & 1.00 & 1.02 \\
\hline 10 & $\begin{array}{c}\text { Stewart et al. (1) } \\
\text { (1994) }\end{array}$ & 0.97 & 0.98 & 0.92 & 0.96 & 0.96 & 0.98 \\
\hline 11 & $\begin{array}{l}\text { Bohm } \\
(1972)\end{array}$ & 1.11 & 1.11 & 1.04 & 1.10 & 1.10 & 1.12 \\
\hline 12 & $\begin{array}{l}\text { Faupel } \\
\text { (1956) }\end{array}$ & 1.15 & 1.15 & 1.11 & 1.15 & 1.16 & 1.17 \\
\hline 13 & $\begin{array}{c}\text { Marin and Rimrott } \\
\text { (1958) }\end{array}$ & 1.11 & 1.12 & 1.03 & 1.09 & 1.09 & 1.12 \\
\hline 14 & $\begin{array}{c}\text { Marin and Sharma } \\
\text { (1958) }\end{array}$ & 1.15 & 1.16 & 1.10 & 1.14 & 1.14 & 1.17 \\
\hline 15 & $\begin{array}{l}\text { Nadai } \\
\text { (1931) }\end{array}$ & 1.16 & 1.15 & 1.12 & 1.15 & 1.16 & 1.18 \\
\hline 16 & $\begin{array}{l}\text { Nadai } \\
\text { (1963) }\end{array}$ & 1.15 & 1.15 & 1.12 & 1.15 & 1.15 & 1.18 \\
\hline 17 & $\begin{array}{l}\text { Soderberg } \\
\text { (1941) }\end{array}$ & 1.16 & 1.15 & 1.12 & 1.15 & 1.16 & 1.18 \\
\hline 18 & $\begin{array}{c}\text { Svensson } \\
(1958)\end{array}$ & 1.11 & 1.11 & 1.04 & 1.10 & 1.10 & 1.12 \\
\hline 19 & $\begin{array}{l}\text { Stewart et al. (2) } \\
\text { (1994) }\end{array}$ & 1.13 & 1.13 & 1.07 & 1.12 & 1.12 & 1.14 \\
\hline 20 & $\begin{array}{l}\text { Zhu and Leis } \\
\text { (2006) }\end{array}$ & 1.05 & 1.06 & 0.99 & 1.04 & 1.04 & 1.06 \\
\hline 21 & $\begin{array}{l}\text { Zhu and Leis } \\
\text { (2007) }\end{array}$ & 1.04 & 1.05 & 1.00 & 1.06 & 1.07 & 1.06 \\
\hline 22 & Proposed equation & 1.02 & 1.02 & 0.99 & 1.02 & 1.02 & 1.04 \\
\hline
\end{tabular}


Table 8 (Cont.) Average Discrepancy (AD) and Standard Error (SE).

\begin{tabular}{|c|c|c|c|c|c|c|c|}
\hline \multicolumn{2}{|r|}{ Model } & \multicolumn{6}{|c|}{ Test Case } \\
\hline No. & $\begin{array}{c}\text { Name } \\
\end{array}$ & $\mathrm{X} 70(2)$ & $\mathrm{X} 70(3)$ & $\mathrm{X} 70(4)$ & $\mathrm{X} 70(5)$ & $\mathrm{X} 80(1)$ & $\mathrm{X} 80(2)$ \\
\hline \multicolumn{2}{|c|}{$\begin{array}{l}\text { Experimental Burst } \\
\text { Pressure (MPa) }\end{array}$} & 23.10 & 23.50 & 40.3 & 23.6 & 27.44 & 27.80 \\
\hline & & \multicolumn{6}{|c|}{ Burst pressures ratio $\left(P_{F P \text { formula }} / P_{\text {exp. }}\right)$} \\
\hline 1 & $\begin{array}{l}\text { ASME } \\
(1962)\end{array}$ & 1.00 & 1.00 & 0.96 & 0.94 & 0.98 & 0.97 \\
\hline 2 & $\begin{array}{l}\text { Barlow OD } \\
\quad(1836)\end{array}$ & 0.98 & 0.98 & 0.93 & 0.93 & 0.96 & 0.95 \\
\hline 3 & $\begin{array}{l}\text { Barlow ID } \\
\text { (1836) }\end{array}$ & 1.02 & 1.02 & 0.99 & 0.96 & 1.00 & 0.99 \\
\hline 4 & $\begin{array}{l}\text { Barlow flow } \\
\qquad(1836)\end{array}$ & 0.99 & 1.00 & 0.94 & 0.91 & 0.92 & 0.96 \\
\hline 5 & $\begin{array}{l}\text { Bailey-Nadai } \\
\text { (1930) }\end{array}$ & 1.00 & 1.00 & 0.95 & 0.94 & 0.98 & 0.97 \\
\hline 6 & $\begin{array}{l}\text { DNV } \\
(2013)\end{array}$ & 1.00 & 1.00 & 0.97 & 0.94 & 0.99 & 0.98 \\
\hline 7 & $\begin{array}{c}\text { Fletcher } \\
(2003)\end{array}$ & 1.03 & 1.04 & 1.01 & 0.97 & 0.96 & 1.00 \\
\hline 8 & $\begin{array}{l}\text { Max. Shear Stress } \\
\text { (2002) }\end{array}$ & 1.00 & 1.00 & 0.96 & 0.94 & 0.98 & 0.97 \\
\hline 9 & $\begin{array}{l}\text { Turner } \\
\text { (1910) }\end{array}$ & 1.00 & 1.00 & 0.96 & 0.94 & 0.98 & 0.97 \\
\hline 10 & $\begin{array}{c}\text { Stewart et al. (1) } \\
\text { (1994) }\end{array}$ & 0.94 & 0.94 & 0.88 & 0.87 & 0.93 & 0.93 \\
\hline 11 & $\begin{array}{l}\text { Bohm } \\
\text { (1972) }\end{array}$ & 1.07 & 1.07 & 0.99 & 0.98 & 1.05 & 1.06 \\
\hline 12 & $\begin{array}{l}\text { Faupel } \\
\text { (1956) }\end{array}$ & 1.15 & 1.15 & 1.10 & 1.08 & 1.10 & 1.12 \\
\hline 13 & $\begin{array}{l}\text { Marin and Rimrott } \\
\qquad(1958)\end{array}$ & 1.06 & 1.06 & 0.98 & 0.96 & 1.04 & 1.05 \\
\hline 14 & $\begin{array}{l}\text { Marin and Sharma } \\
\qquad(1958)\end{array}$ & 1.12 & 1.12 & 1.07 & 1.03 & 1.10 & 1.11 \\
\hline 15 & $\begin{array}{l}\text { Nadai } \\
\text { (1931) }\end{array}$ & 1.16 & 1.16 & 1.11 & 1.09 & 1.13 & 1.12 \\
\hline 16 & $\begin{array}{l}\text { Nadai } \\
\text { (1963) }\end{array}$ & 1.15 & 1.15 & 1.10 & 1.08 & 1.13 & 1.12 \\
\hline 17 & $\begin{array}{l}\text { Soderberg } \\
\text { (1941) }\end{array}$ & 1.16 & 1.16 & 1.11 & 1.09 & 1.13 & 1.12 \\
\hline 18 & $\begin{array}{c}\text { Svensson } \\
\text { (1958) }\end{array}$ & 1.07 & 1.07 & 0.99 & 0.98 & 1.05 & 1.06 \\
\hline 19 & $\begin{array}{c}\text { Stewart et al. (2) } \\
\text { (1994) }\end{array}$ & 1.10 & 1.10 & 1.04 & 1.02 & 1.08 & 1.08 \\
\hline 20 & $\begin{array}{l}\text { Zhu and Leis } \\
\text { (2006) }\end{array}$ & 1.02 & 1.02 & 0.96 & 0.94 & 1.00 & 1.01 \\
\hline 21 & $\begin{array}{l}\text { Zhu and Leis } \\
(2007)\end{array}$ & 1.05 & 1.05 & 0.99 & 0.98 & 1.00 & 1.02 \\
\hline 22 & Proposed equation & 1.02 & 1.02 & 0.98 & 0.96 & 1.00 & 0.99 \\
\hline
\end{tabular}


Table 8 (Cont.) Average Discrepancy (AD) and Standard Error (SE).

\begin{tabular}{|c|c|c|c|c|c|c|}
\hline \multicolumn{2}{|r|}{ Model } & \multicolumn{2}{|c|}{ Test Case } & \multirow{2}{*}{$\mathrm{AD}$} & \multirow{2}{*}{ SE } & \multirow{2}{*}{$\begin{array}{c}\text { SE } \\
\text { Ranking }\end{array}$} \\
\hline No. & Name & $\mathrm{X} 80$ (3) & X80 (4) & & & \\
\hline \multicolumn{2}{|c|}{$\begin{array}{l}\text { Experimental Burst Pressure } \\
(\mathrm{MPa})\end{array}$} & 42 & 21.90 & - & - & - \\
\hline & & $\begin{array}{l}\text { Burst p1 } \\
\left(P_{F P f o}\right.\end{array}$ & $\begin{array}{l}\text { res ratio } \\
\left(P_{\text {exp. }}\right)\end{array}$ & - & - & - \\
\hline 1 & $\begin{array}{l}\text { ASME } \\
(1962)\end{array}$ & 1.00 & 1.00 & $-1.439 \%$ & $0.690 \%$ & 6 \\
\hline 2 & $\begin{array}{l}\text { Barlow OD } \\
\quad(1836)\end{array}$ & 0.99 & 0.98 & $-2.998 \%$ & $1.019 \%$ & 9 \\
\hline 3 & $\begin{array}{l}\text { Barlow ID } \\
\text { (1836) }\end{array}$ & 1.02 & 1.01 & $1.000 \%$ & $0.612 \%$ & 3 \\
\hline 4 & $\begin{array}{l}\text { Barlow flow } \\
\quad(1836)\end{array}$ & 0.96 & 0.99 & $-2.790 \%$ & $1.175 \%$ & 11 \\
\hline 5 & $\begin{array}{l}\text { Bailey-Nadai } \\
\text { (1930) }\end{array}$ & 1.00 & 1.00 & $-1.324 \%$ & $0.691 \%$ & 7 \\
\hline 6 & $\begin{array}{l}\text { DNV } \\
(2013)\end{array}$ & 1.00 & 1.00 & $-0.636 \%$ & $0.587 \%$ & 2 \\
\hline 7 & $\begin{array}{l}\text { Fletcher } \\
(2003)\end{array}$ & 0.99 & 1.03 & $1.042 \%$ & $0.756 \%$ & 8 \\
\hline 8 & $\begin{array}{l}\text { Max. Shear Stress } \\
\text { (2002) }\end{array}$ & 1.00 & 1.00 & $-1.041 \%$ & $0.628 \%$ & 5 \\
\hline 9 & $\begin{array}{l}\text { Turner } \\
(1910)\end{array}$ & 1.00 & 1.00 & $-1.027 \%$ & $0.626 \%$ & 4 \\
\hline 10 & $\begin{array}{c}\text { Stewart et al. (1) } \\
\text { (1994) }\end{array}$ & 0.96 & 0.95 & $-5.882 \%$ & $1.877 \%$ & 13 \\
\hline 11 & $\begin{array}{l}\text { Bohm } \\
(1972)\end{array}$ & 1.09 & 1.09 & $6.975 \%$ & $2.239 \%$ & 15 \\
\hline 12 & $\begin{array}{l}\text { Faupel } \\
(1956)\end{array}$ & 1.14 & 1.15 & $13.468 \%$ & $3.809 \%$ & 19 \\
\hline 13 & $\begin{array}{l}\text { Marin and Rimrott } \\
\qquad(1958)\end{array}$ & 1.08 & 1.08 & $6.317 \%$ & $2.160 \%$ & 14 \\
\hline 14 & $\begin{array}{l}\text { Marin and Sharma } \\
\qquad(1958)\end{array}$ & 1.13 & 1.13 & $12.075 \%$ & $3.485 \%$ & 18 \\
\hline 15 & $\begin{array}{l}\text { Nadai } \\
\text { (1931) }\end{array}$ & 1.16 & 1.15 & $14.284 \%$ & $4.014 \%$ & 22 \\
\hline 16 & $\begin{array}{l}\text { Nadai } \\
\text { (1963) }\end{array}$ & 1.15 & 1.15 & $13.941 \%$ & $3.925 \%$ & 20 \\
\hline 17 & $\begin{array}{l}\text { Soderberg } \\
(1941)\end{array}$ & 1.16 & 1.15 & $14.268 \%$ & $4.009 \%$ & 21 \\
\hline 18 & $\begin{array}{l}\text { Svensson } \\
(1958)\end{array}$ & 1.09 & 1.09 & $7.038 \%$ & $2.253 \%$ & 16 \\
\hline 19 & $\begin{array}{l}\text { Stewart et al. (2) } \\
\text { (1994) }\end{array}$ & 1.11 & 1.11 & $9.812 \%$ & $2.893 \%$ & 17 \\
\hline 20 & $\begin{array}{l}\text { Zhu and Leis } \\
\text { (2006) }\end{array}$ & 1.04 & 1.03 & $1.945 \%$ & $1.097 \%$ & 10 \\
\hline 21 & $\begin{array}{l}\text { Zhu and Leis } \\
(2007)\end{array}$ & 1.03 & 1.05 & $3.241 \%$ & $1.186 \%$ & 12 \\
\hline 22 & Proposed equation & 1.01 & 1.01 & $0.653 \%$ & $0.587 \%$ & 1 \\
\hline
\end{tabular}




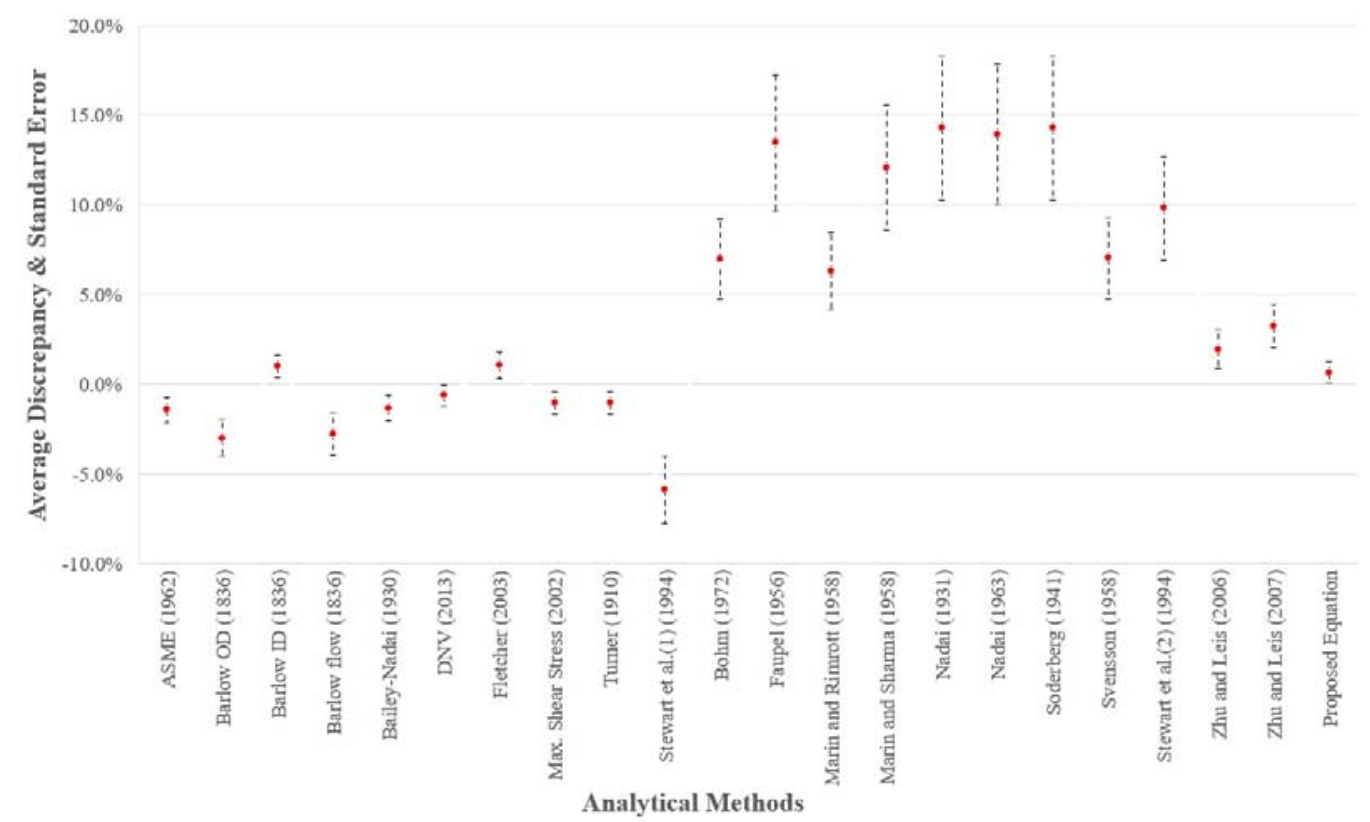

Figure 12 Average discrepancy and standard errors in association with the experimental results and the prediction by analytical methods.

According to the results indicated in the Table 8 and Figure 12, the predicted burst pressures calculated by the proposed empirical formula show the best agreement with the experimental results with standard error of $0.587 \%$ and average discrepancy of $0.653 \%$.

It is observed from Figure 12 that in general, the error bounds of the pipeline burst pressure predictions using the formulae based on Tresca and the average shear stress criterion categories are less than the error bounds based on the von Mises criterion category. The results from the former category tend to better predict the experimental results, and the latter category generally tends to overestimate the burst pressure. Nevertheless, the only exception in the latter category is the proposed formula, which produces similar results to those from DNV and Barlow ID formulae.

From the above results, it is confirmed that the proposed methodology, that is, the methodology of performing the nonlinear FEA based on the tangent modulus calculated 
using the strain in the UTS calculated by the proposed formula, is reliable.

\section{Conclusions}

A study was carried out in order to develop a new methodology for the prediction of the burst pressure for API 5L X grade flawless pipelines.

First of all, an empirical formula to estimate the strain at UTS was derived from the pipeline API 5L X grade material coupon test data. This formula was then used to predict the strain at UTS and the calculated strain at UTS was employed to calculate the tangent modulus in order to consider the strain hardening effect within the FEA material model.

Based on the defined material model by the use of the calculated strain at UTS, a comprehensive nonlinear FEA was performed on 529 pipelines of differing material properties and geometries that were subject to an internal pressure load. The results of the parametric study were used to derive a new empirical formula that predicts the burst pressure of a flawless pipeline. This formula consists of $\sigma_{U T S}, \sigma_{\text {yield }}$ to $\sigma_{U T S}$ ratio, and the outer diameter to wall thickness ratio. The predictions of burst pressure for the flawless pipeline by the proposed formula were compared with the results of 14 pipeline burst pressure experimental results together with the results based on the conventional formulae. It was found that the best agreement was achieved between the burst pressure calculated by the proposed formula and the burst test results. In addition, the proposed formula is shown to give the most accurate predictions of the 22 formulae based on the standard error criteria. Therefore, it can be concluded that the burst pressure prediction formula derived by following the proposed methodology can calculate an accurate burst pressure for the API 5L X grade flawless pipelines from X52 to X80 and D/t range from 10 to 96 . 


\section{References}

API, 2004. API 5L: Specification for Line Pipe, Washington, DC, USA: American Petroleum Institute.

ASME, 1962. ASME Boiler and Pressure Vessel Code, New York, NY, USA: American Society Mechanical Engineers.

ASME, 1971. ASME Boiler and Pressure Vessel Code; Section III. Division 1, New York, NY, USA: American Society Mechanical Engineers.

ASME, 1974. ASME Boiler and Pressure Vessel Code; Section III. Division 1 Par. 1430, New York, NY, USA: American Society Mechanical Engineers.

ASME, 1986. ASME Boiler and Pressure Vessel Code; Section XI. Division 2, New York, NY, USA: American Society Mechanical Engineers.

Bailey R.W., 1930. Thick-walled tubes and cylinders under high pressure and temperatures. Engineering. 129, 772-777.

Barlow P., 1836. On the force excited by hydraulic pressure in Bramah press; the resisting power of the cylinder, and rules for computing the thickness of metal for presses of various powers and dimensions. Trans. Institution of Civil Engineers. 1, 133139

Bohm G.J., 1972. Pressure Vessels and Piping: Design and Analysis: A Decade of Progress, New York, USA: American Society Mechanical Engineers. 1, 23-32.

Chen X., Gao B., Wang X., 2016. Evaluation of limit load analysis for pressure vesselsPart I: Linear and nonlinear methods. Steel and Composite Structures, 1391-1415. Christopher T., Rama Sarma B.S.V., Govindan Potti P.K., Nageswara Rao B., Sankarnarayanasamy K., 2002. A comparative study on failure pressure estimations of unflawed cylindrical vessels. International Journal of Pressure Vessels and Piping. 79, 53-66.

Demir H.H., Drueker D.C., 1963. An Experimental Study of Cylindrical Shells under Ring Loads. Prager Anniversary Volume, 205-220.

DNV, 2008. Recommended Practice DNV-RP-D101. Norway: Det Norske Veritas.

DNV, 2013. Offshore Standard DNV-OS-F101. Norway: Det Norske Veritas.

Evans, J.D., 1996. Straightforward Statistics for the Behavioural Sciences. Brooks/Cole Publishing Company.

Faupel, J.H., 1956. Yielding and bursting characteristics of heavy walled cylinders. Trans. American Society Mechanical Engineers. 78, 1031-1064. 
Fletcher, L., 2003. Private communication.

Gerdeen, J.C., 1979. A critical evaluation of plastic behavior data and a united definition of plastic loads for pressure components. WRC Bulletin. 254.

Kirkwood, M.G., 1986. Finite element stress analysis of an equal diameter branch pipe intersection subjected to out-of-plane and twisting moments. Strain Anal. 21(1), 171-183.

Kirkwood, M.G., 1989. Techniques for measuring plastic loads in branch pipe connections loads by pressure and in-plane moments. Pipework Engineering and Operation. London. UK, 197-208.

Law, M., Bowie, G., 2007. Prediction of failure strain and burst pressure in high yieldto-tensile strength ratio linepipe. International Journal of Pressure Vessels and Piping. 84, 487-492.

Liessem, A., Graef, M.K., Knauf, G., Marewski, U., 2004. Influence of thermal treatment on mechanical properties on UOE linepipe. Proceedings of the 4th International Conference of Pipeline Technology. Ostend. Belgium, 1263-1281.

Lynch, M.A., Moffat, D.G., 2000. Limit load for cracked piping branch junctions under pressure and branch out-of-plane bending. International Journal of Pressure Vessels and Piping. 77(5), 185-194.

MacDonald, B.J., 2007. Practical Stress Analysis with Finite Elements. Ireland: Glasnevin Publishing.

Marine, J., Rimrott, F.P.J., 1958. Design of thick walled pressure vessels based upon the plastic range.Wel Res Coun Bullet 41.

Marin, J., Sharma, M., 1958. Design of a thin walled cylindrical vessel based upon plastic range and considering anisotropy. Wel Res Coun Bullet 40.

Miklus, S., Kosel, F., 1991. Plastic collapse of pipe bi-furcation, International Journal of Pressure Vessels and Piping, 79-92.

Muscat, M., Mackenzie, D., Hamilton, R., 2003. A work criterion plastic collapse, International Journal of Pressure Vessels and Piping. 80(1), 49-58.

Nadai, A., 1931. Plasticity: a mechanics of the plastic state of matter. New York: McGraw-Hill Book Co.

Nadai, A., 1963. Theory of flow and fracture of solids. Vol. 2. New York: McGraw-Hill Book Co. 
Norman, E., 2013. Mechanical Behavior of Materials, England: Pearson Education Limited

Patel, D.M., Kumar, B., 2014. Pressure vessel limit load estimation by FEM and experimental method. International Journal of Innovative Research in Advanced Engineering. 9, 109-114.

Save, M., 1972. Experimental verification of plastic limit analysis of tori-spherical and tori-conical heads. Pressure Vessel and Piping: Design and Analysis. 1(1), 382416

Schroeder, J., 1980. A plastic modulus approach to experimental limit loads. ASME Paper No. 80-C2/PVP-1.

Schroeder, J., 1985. Experimental limit couples for branch moment loads on 4 in. ANSI B16.9 Tees. WRC Bulletin 304.

Soderberg, C.R., 1958. Interpretation of creep tests on tubes. Trans. American Society Mechanical Engineers. 63, 737-748.

Stewart, G., Klever, F.J., Ritchie, D., 1994. An analytical model to predict the burst capacity of pipelines. International conference. Paper presented at: $13^{\text {th }}$ International conference on Offshore Mechanics and Arctic engineering; February 27-March 3; Houston, TX, USA.

Su, W.X., Zheng, J.Y., Kai, F.M., 2005. A 5\% maximum principal strain criterion to prevent gross plastic deformation. Vessel Technol. 22(12), 17-21.

Svensson, N.L., 1958. Bursting pressure of cylindrical and spherical pressure vessels. Trans. American Society Mechanical Engineers. 80, 89-96.

Townley, C.H.A., Findlay, G.E., Goodman, A.M., Stanley, P., 1971. Elastic-plastic computations a basic for design charts for tori-spherical pressure vessel ends. Proceedings of the Institution of Mechanical Engineers. Part E: Journal of Process Mechanical Engineering. 185(63), 869-877.

Turner, L.B., 1910. The stresses in a thick hollow cylinder subjected to internal pressure. Trans Camb Philos Soc. 21, 377-396.

Zhang, S.H., Zhao, D.W., Wang, X.N., 2014. Influence of yield to tensile strength ratio $(\mathrm{Y} / \mathrm{T})$ on failure assessment of defect free and corroded X70 steel pipeline. Journal of Central South University. 21, 460-465 
Zhu, X.K., Leis, B.N., 2005. Influence of yield to tensile strength ratio on failure assessment of corroded pipelines. ASME transactions. American Society Mechanical Engineers. 127, 436-442.

Zhu, X.K., Leis, B.N., 2007. Theoretical and numerical predictions of burst pressure of pipelines. Journal of Pressure Vessel Technology. 129, 644-652.

Zhu, X.K., Leis, B.N., 2010. Prediction and comparison of burst pressure for line pipes. International Pipeline Conference. Paper presented at: $8^{\text {th }}$ International Pipeline Conference; September 27-October 1; Calgary, Alberta, Canada.

Zhu, X.K., Leis, B.N., 2012. Evaluation of burst pressure prediction models for line pipes. International Journal of Pressure Vessels and Piping. 89, 85-97. 


\section{Appendix}

Table A.1 Geometric information for the parametric analysis.

\begin{tabular}{|c|c|c|c|c|c|c|}
\hline \multirow[b]{2}{*}{ No. } & \multicolumn{3}{|c|}{$\mathrm{X} 52, \mathrm{X} 56, \mathrm{X} 60, \mathrm{X} 65$ and X70 } & \multicolumn{3}{|c|}{$\mathrm{X} 80$} \\
\hline & $\begin{array}{c}\text { Outer dia. } \\
(D, m m)\end{array}$ & $\begin{array}{c}\text { thickness } \\
(t, \mathrm{~mm})\end{array}$ & $D / t$ & $\begin{array}{c}\text { Outer dia. } \\
(D, m m)\end{array}$ & $\begin{array}{c}\text { thickness } \\
(t, \mathrm{~mm})\end{array}$ & $D / t$ \\
\hline 1 & 60.3 & 3.9 & 15.42 & 323.9 & 4.775 & 67.82 \\
\hline 2 & 60.3 & 5.5 & 10.88 & 323.9 & 5.156 & 62.81 \\
\hline 3 & 73.0 & 5.2 & 14.15 & 323.9 & 5.563 & 58.22 \\
\hline 4 & 73.0 & 7.0 & 10.41 & 323.9 & 6.350 & 51.00 \\
\hline 5 & 88.9 & 5.5 & 16.19 & 323.9 & 7.137 & 45.37 \\
\hline 6 & 88.9 & 7.6 & 11.67 & 323.9 & 7.925 & 40.87 \\
\hline 7 & 114.3 & 6.0 & 18.99 & 323.9 & 8.382 & 38.64 \\
\hline 8 & 114.3 & 8.6 & 13.35 & 323.9 & 8.738 & 37.06 \\
\hline 9 & 114.3 & 11.1 & 10.30 & 323.9 & 9.525 & 34.00 \\
\hline 10 & 141.3 & 6.6 & 21.57 & 323.9 & 10.312 & 31.40 \\
\hline 11 & 141.3 & 9.5 & 14.84 & 323.9 & 11.125 & 29.11 \\
\hline 12 & 168.3 & 7.1 & 23.67 & 323.9 & 12.700 & 25.50 \\
\hline 13 & 168.3 & 11.0 & 15.34 & 355.6 & 4.775 & 74.47 \\
\hline 14 & 168.3 & 12.7 & 13.25 & 355.6 & 5.156 & 68.97 \\
\hline 15 & 168.3 & 14.3 & 11.79 & 355.6 & 5.563 & 63.93 \\
\hline 16 & 219.1 & 6.4 & 34.50 & 355.6 & 6.350 & 56.00 \\
\hline 17 & 219.1 & 8.2 & 26.78 & 355.6 & 7.137 & 49.82 \\
\hline 18 & 219.1 & 10.3 & 21.25 & 355.6 & 7.925 & 44.87 \\
\hline 19 & 219.1 & 12.7 & 17.25 & 355.6 & 8.382 & 42.42 \\
\hline 20 & 219.1 & 15.9 & 13.80 & 355.6 & 8.738 & 40.70 \\
\hline 21 & 219.1 & 19.1 & 11.50 & 355.6 & 9.525 & 37.33 \\
\hline 22 & 273.0 & 6.4 & 42.99 & 355.6 & 10.312 & 34.48 \\
\hline 23 & 273.0 & 9.3 & 29.45 & 355.6 & 11.125 & 31.96 \\
\hline 24 & 273.0 & 12.7 & 21.50 & 355.6 & 12.700 & 28.00 \\
\hline 25 & 273.0 & 15.9 & 17.19 & 406.4 & 6.350 & 64.00 \\
\hline 26 & 273.0 & 19.1 & 14.33 & 406.4 & 7.137 & 56.94 \\
\hline 27 & 273.0 & 21.4 & 12.73 & 406.4 & 7.925 & 51.28 \\
\hline 28 & 273.0 & 25.4 & 10.75 & 406.4 & 8.738 & 46.51 \\
\hline 29 & 323.8 & 9.5 & 33.98 & 406.4 & 9.525 & 42.67 \\
\hline 30 & 323.8 & 10.3 & 31.41 & 406.4 & 10.312 & 39.41 \\
\hline
\end{tabular}


Table A.2 (Cont.) Geometric information for the parametric analysis.

\begin{tabular}{|c|c|c|c|c|c|c|}
\hline \multirow{2}{*}{ No. } & \multicolumn{3}{|c|}{ X52, X56, X60, X65 and X70 } & \multicolumn{3}{|c|}{$\mathrm{X} 80$} \\
\hline & $\begin{array}{c}\text { Outer dia. } \\
(D, m m)\end{array}$ & $\begin{array}{l}\text { thickness } \\
(t, m m)\end{array}$ & $D / t$ & $\begin{array}{l}\text { Outer dia. } \\
(D, m m)\end{array}$ & $\begin{array}{c}\text { thickness } \\
(t, m m)\end{array}$ & $D / t$ \\
\hline 31 & 323.8 & 12.7 & 25.50 & 406.4 & 11.125 & 36.53 \\
\hline 32 & 323.8 & 14.3 & 22.69 & 406.4 & 11.913 & 34.12 \\
\hline 33 & 323.8 & 15.9 & 20.39 & 406.4 & 12.700 & 32.00 \\
\hline 34 & 323.8 & 17.5 & 18.52 & 406.4 & 14.275 & 28.47 \\
\hline 35 & 323.8 & 19.1 & 17.00 & 406.4 & 15.875 & 25.60 \\
\hline 36 & 323.8 & 21.4 & 15.10 & 457.2 & 6.350 & 72.00 \\
\hline 37 & 323.8 & 25.4 & 12.75 & 457.2 & 7.137 & 64.06 \\
\hline 38 & 323.8 & 31.8 & 10.20 & 457.2 & 7.925 & 57.69 \\
\hline 39 & 355.6 & 9.5 & 37.31 & 457.2 & 8.738 & 52.33 \\
\hline 40 & 355.6 & 11.1 & 31.95 & 457.2 & 9.525 & 48.00 \\
\hline 41 & 355.6 & 12.7 & 28.00 & 457.2 & 10.312 & 44.33 \\
\hline 42 & 355.6 & 15.9 & 22.39 & 457.2 & 11.125 & 41.10 \\
\hline 43 & 355.6 & 19.1 & 18.67 & 457.2 & 11.913 & 38.38 \\
\hline 44 & 355.6 & 25.4 & 14.00 & 457.2 & 12.700 & 36.00 \\
\hline 45 & 355.6 & 31.8 & 11.20 & 457.2 & 14.275 & 32.03 \\
\hline 46 & 406.4 & 9.5 & 42.64 & 457.2 & 15.875 & 28.80 \\
\hline 47 & 406.4 & 12.7 & 32.00 & 508.0 & 6.350 & 80.00 \\
\hline 48 & 406.4 & 14.3 & 28.48 & 508.0 & 7.137 & 71.17 \\
\hline 49 & 406.4 & 15.9 & 25.59 & 508.0 & 7.925 & 64.10 \\
\hline 50 & 406.4 & 16.7 & 24.39 & 508.0 & 8.738 & 58.14 \\
\hline 51 & 406.4 & 17.5 & 23.25 & 508.0 & 9.525 & 53.33 \\
\hline 52 & 406.4 & 19.1 & 21.33 & 508.0 & 10.312 & 49.26 \\
\hline 53 & 406.4 & 21.4 & 18.96 & 508.0 & 11.125 & 45.66 \\
\hline 54 & 406.4 & 25.4 & 16.00 & 508.0 & 11.913 & 42.64 \\
\hline 55 & 406.4 & 31.0 & 13.11 & 508.0 & 12.700 & 40.00 \\
\hline 56 & 406.4 & 31.8 & 12.80 & 508.0 & 14.275 & 35.59 \\
\hline 57 & 406.4 & 38.1 & 10.67 & 508.0 & 15.875 & 32.00 \\
\hline 58 & 457.2 & 12.7 & 36.00 & 558.8 & 6.350 & 88.00 \\
\hline 59 & 457.2 & 15.9 & 28.79 & 558.8 & 7.137 & 78.29 \\
\hline 60 & 457.2 & 19.1 & 24.00 & 558.8 & 7.925 & 70.51 \\
\hline
\end{tabular}


Table A.3 (Cont.) Geometric information for the parametric analysis.

\begin{tabular}{|c|c|c|c|c|c|c|}
\hline \multirow{2}{*}{ No. } & \multicolumn{3}{|c|}{$\mathrm{X} 52, \mathrm{X} 56, \mathrm{X} 60, \mathrm{X} 65$ and X70 } & \multicolumn{3}{|c|}{$\mathrm{X} 80$} \\
\hline & $\begin{array}{l}\text { Outer dia. } \\
(D, m m)\end{array}$ & $\begin{array}{l}\text { thickness } \\
(t, \mathrm{~mm})\end{array}$ & $D / t$ & $\begin{array}{l}\text { Outer dia. } \\
(D, m m)\end{array}$ & $\begin{array}{l}\text { thickness } \\
(t, \mathrm{~mm})\end{array}$ & $D / t$ \\
\hline 61 & 457.2 & 23.8 & 19.19 & 558.8 & 8.738 & 63.95 \\
\hline 62 & 457.2 & 25.4 & 18.00 & 558.8 & 9.525 & 58.67 \\
\hline 63 & 457.2 & 31.8 & 14.40 & 558.8 & 10.312 & 54.19 \\
\hline 64 & 457.2 & 38.1 & 12.00 & 558.8 & 11.125 & 50.23 \\
\hline 65 & 457.2 & 45.2 & 10.11 & 558.8 & 11.913 & 46.91 \\
\hline 66 & 508.0 & 12.7 & 40.00 & 558.8 & 12.700 & 44.00 \\
\hline 67 & 508.0 & 15.9 & 31.99 & 558.8 & 14.275 & 39.15 \\
\hline 68 & 508.0 & 17.5 & 29.06 & 558.8 & 15.875 & 35.20 \\
\hline 69 & 508.0 & 19.1 & 26.67 & 609.6 & 6.350 & 96.00 \\
\hline 70 & 508.0 & 25.4 & 20.00 & 609.6 & 7.137 & 85.41 \\
\hline 71 & 508.0 & 26.2 & 19.39 & 609.6 & 7.925 & 76.92 \\
\hline 72 & 508.0 & 31.8 & 16.00 & 609.6 & 8.738 & 69.77 \\
\hline 73 & 508.0 & 32.5 & 15.63 & 609.6 & 9.525 & 64.00 \\
\hline 74 & 508.0 & 38.1 & 13.33 & 609.6 & 10.312 & 59.11 \\
\hline 75 & 508.0 & 50.8 & 10.00 & 609.6 & 11.125 & 54.79 \\
\hline 76 & 559.0 & 12.7 & 44.02 & 609.6 & 11.913 & 51.17 \\
\hline 77 & 559.0 & 19.1 & 29.34 & 609.6 & 12.700 & 48.00 \\
\hline 78 & 559.0 & 25.4 & 22.01 & 609.6 & 14.275 & 42.70 \\
\hline 79 & 559.0 & 31.8 & 17.61 & 609.6 & 15.875 & 38.40 \\
\hline 80 & 559.0 & 38.1 & 14.67 & & \multirow{11}{*}{-} & \\
\hline 81 & 610.0 & 9.5 & 64.08 & & & \\
\hline 82 & 610.0 & 12.7 & 48.03 & & & \\
\hline 83 & 610.0 & 14.3 & 42.75 & & & \\
\hline 84 & 610.0 & 15.9 & 38.41 & & & \\
\hline 85 & 610.0 & 17.5 & 34.90 & & & \\
\hline 86 & 610.0 & 19.1 & 32.02 & & & \\
\hline 87 & 610.0 & 25.4 & 24.02 & & & \\
\hline 88 & 610.0 & 31.8 & 19.21 & & & \\
\hline 89 & 610.0 & 38.1 & 16.01 & & & \\
\hline 90 & 610.0 & 50.8 & 12.01 & & & \\
\hline
\end{tabular}

